\title{
Experimental investigation and modeling of fuel wall films from gasoline direct injection nozzles
}

\author{
Vanessa Da Silva Cruz Lis*1, Wolfgang Samenfink ${ }^{1}$, Erik Schünemann ${ }^{1}$, Michael Wensing ${ }^{2}$ \\ ${ }^{1}$ Powertrain Solutions, Robert Bosch $\mathrm{GmbH}$, Schwieberdingen, Germany \\ ${ }^{2}$ Institute of Engineering Thermodynamics, FAU, Erlangen, Germany \\ *Corresponding author email: Vanessa.DaSilvaCruzLis@de.bosch.com
}

\begin{abstract}
The reduction of fuel wall films is necessary to limit particulate emissions in combustion engines. Especially under cold conditions and load steps, the developing wall films might not evaporate completely before the start of combustion. The investigation of fuel wall films is the basis for understanding the parametric conditions that promote wall film formation caused by multi-hole direct injection nozzles. Fundamental experiments are described in this work with two different measurement techniques to collect data on wall film parameters under a large set of surrounding conditions. The results of these experiments are discussed and compared to the results of an adapted wall film evaporation model from the literature. The differences to the measurements and the limitations of the model and their causes are considered.
\end{abstract}

\section{Keywords}

gasoline direct injection, fuel wall films, particulate emissions

\section{Introduction}

Soot particles are generated in combustion engines when globally or locally understoichiometric mixtures of fuel and air combined with high surrounding temperatures appear. This occurs when the mixture preparation in the gas phase is not sufficient or when fuel wall films are formed. In gasoline direct injection engines, these wall films can appear on the piston, the liner, the valves or on the tip of the injection nozzle and to an increased degree during the engine start where the surfaces are still cold and wall films thus evaporate too slowly. Liquid films that do not completely evaporate before the start of combustion then evaporate quickly during the combustion process due to the increased temperatures and lead to fuel rich regions inside the engine or even to so-called 'pool fires' which result in particulate emissions [1]. Therefore, the investigation of fuel wall films is a central task within the effort to reduce particulate emissions especially under cold conditions. Wall film formation in engines is a complex process that has been described in many previous publications [2] - [4]. Since the injection nozzle is the origin of the spray formation processes and therefore of the wall film build-up, a measurement procedure is necessary to identify wall film parameters for various nozzle geometries and surrounding conditions. To understand the temporal development of those wall films and their evaporation behaviour, investigations can be performed using different measurement techniques. These can be grouped into optical, gravimetric, electrical and acoustic techniques and a good overview is given in [5]. Complex and therefore timeconsuming measurement techniques, such as the widely used laser-induced fluorescence (LIF), may not be well-suited when a large number of individual measurements is needed. To generate input data for design of experiment (DoE) models, large variations of many different influencing parameters are needed and fast and robust measurements are thus ideal. In upcoming investigations, a DoE of the varied parameters and the nozzle geometry is intended.

\section{Experimental Setup}

In this work a simple and quick experiment suitable for implementation in a pressure chamber was developed, Figure 1. It can identify various wall film parameters for a large set of spray 
layouts and surrounding conditions independent of the parametric interrelations of an operating engine. The first selected measurement technique is the visualization of the wall film with a high-speed camera. Thereby, quantitative wall film parameters like the wall film area and the evaporation time can be recorded with high temporal resolution. The view of the camera is almost perpendicular to the wall where the fuel film accumulates. By illuminating the roughened surface of the wall plate with LED lights through the lateral flanges of the chamber, the contrast between the wetted darker area and the dry wall becomes visible. As in a refractive index matching (RIM) experiment, the presence of liquid films changes the local roughness and thus the way light is scattered on the surface; the main difference is that RIM relies on transparent surfaces and thus allows a visualization through the back side, which is not disturbed by the spray, and a limited calibration of the relationship between scattered light and film thickness. Simultaneously, a dynamic load cell inside the chamber records the film mass that accumulates on the wall. The small wall film mass in the region of ten milligrams makes a fast and sensitive load cell necessary.

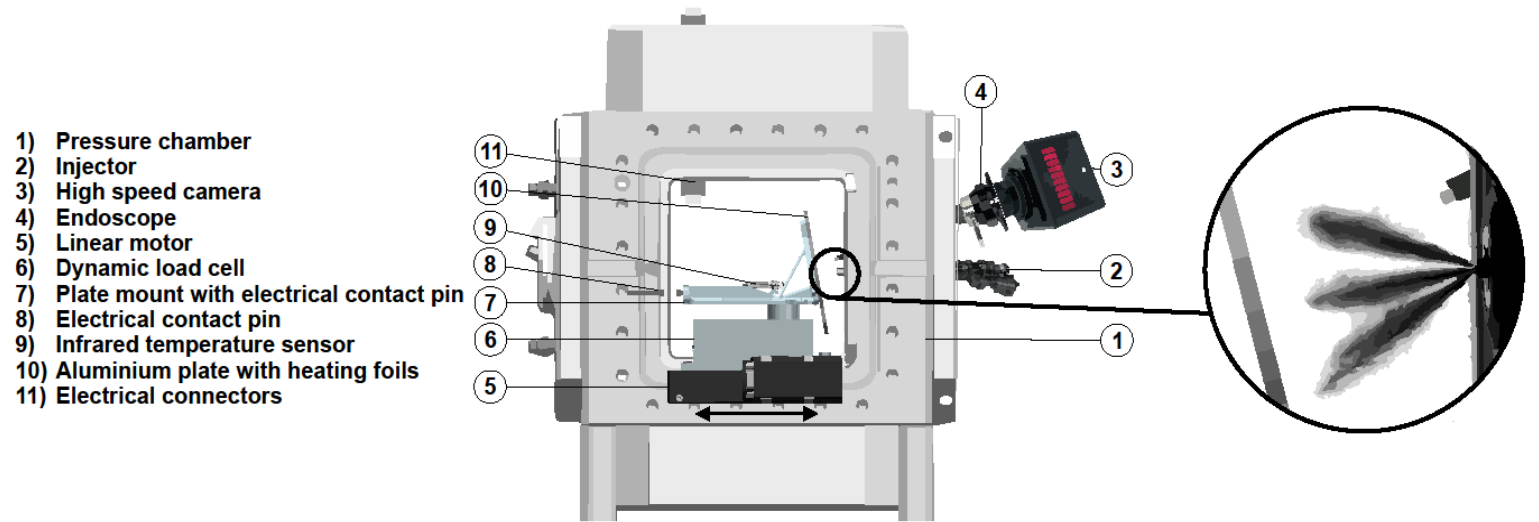

Figure 1. Experimental setup for simultaneous high-speed imaging and weighing of fuel wall film

In an optically accessible pressure chamber (1), a Bosch HDEV 5 six-hole gasoline injector is mounted in the right-hand side lateral flange. In the same flange, an endoscopic access (4) has been created to mount a high-speed camera (3, Photron AX200). A linear motor (5) is mounted on the chamber floor. An aluminium plate (10) is attached to a mount (7) on top of a dynamic load cell (6, Sartorius WZA224-ND) which is mounted on the linear motor. The aluminium plate is positioned at an angle of ten degrees to the vertical axis to compensate for the tilt of the spray axis to the injector axis. With the linear motor, the weighing system can be moved toward or away from the injection nozzle. The flat aluminium plate represents the piston inside a gasoline engine and the variable distance between the plate and the nozzle translates to the piston position inside an engine at different injection timings. For wall temperature adjustment, electrical contact pins are fixed to the plate mount and the back flange of the pressure chamber. When the system is in the left-most position and through heating foils, which are attached to the back of the aluminium plate, the plate itself is heated. During the measurement, a contactless measurement of the plate temperature is possible with an infrared temperature sensor (9) located behind the aluminium plate.

The parametric variation of the measurements is presented in Table 1. If not otherwise stated, the standard measurement conditions apply for the presented results and timings refer to the start of energizing of the injector as $t=0 \mathrm{~s}$. The fuel used in these investigations consists of three components that approximately represent the boiling curve of gasoline, as described in [6]. Its composition and some component properties can be found in Table 2 (all for atmospheric conditions and $273 \mathrm{~K}$ ). Since gasoline fuel tends to have varying properties and it is complex to describe its evaporation behaviour for models and simulation, a fuel reduced 
to three components gives the opportunity for more reliable models and to conduct reproducible measurements. It was also contemplated to verify the measurement results with an alternative measurement technique like laser induced fluorescence. As gasoline contains various uncontrolled fluorescing components, it could not be used for quantitative measurements.

Table 1 - Parametric variation of the measurements

\begin{tabular}{c|cc}
\hline Parameter & Range & Standard conditions \\
\hline Fuel pressure $\left(p_{\text {Fuel }}\right)$ & $10 \ldots 35 \mathrm{MPa}$ & $35 \mathrm{MPa}$ \\
Fuel temperature $\left(T_{\text {Fuel }}\right)$ & $298 \ldots 393 \mathrm{~K}$ & $298 \mathrm{~K}$ \\
Injected fuel mass $\left(m_{\text {Inj }}\right)$ & $15 \ldots 55 \mathrm{mg}$ & $35 \mathrm{mg}$ \\
Chamber pressure $\left(p_{\text {Chamber }}\right)$ & $0.03 \ldots 0.21 \mathrm{MPa}$ & $0.1 \mathrm{MPa}$ \\
Nozzle-injector distance $\left(d_{\text {Inj }}\right)$ & $25 \ldots 65 \mathrm{~mm}$ & $35 \mathrm{~mm}$ \\
Wall temperature $\left(T_{\text {Wall }}\right)$ & $298 \ldots 373 \mathrm{~K}$ & $298 \mathrm{~K}$
\end{tabular}

Table 2 - Fuel properties

\begin{tabular}{c|ccc}
\hline Fuel component & Volume fraction [\%] & Density $\left[\mathrm{kg} / \mathrm{m}^{3}\right]$ & Boiling point $[\mathrm{K}]$ \\
\hline n-Pentane & 36 & 630 & 309 \\
iso-Octane & 46 & 690 & 372 \\
n-Undecane & 18 & 740 & 469
\end{tabular}

\section{Experimental Results}

Since the spray formation and evaporation processes are not measured in this investigation, they need to be taken into account in the analyzation of the wall film. From the high-speed video endoscopy, wall film parameters like the area or the evaporation time can be evaluated. A typical curve of the wall film area over time is shown in Figure 2 for the standard measurement conditions, a fuel temperature of $393 \mathrm{~K}$ and a wall temperature of $333 \mathrm{~K}$. After the end of injection, the spray no longer inhibits film visibility and the wall film area increases for a few milliseconds as the wall film is still in motion. After the maximum wall film area is reached, the wall film area decreases due to evaporation. The reduction of the wall film area is also visible in the binarized wall film images in Figure $\mathbf{5}$ and Figure $\mathbf{6}$ which represent the maximum wall film area and the wall film at 10 seconds respectively. Since the wall temperature is high in this measurement, the wall film is fully evaporated after around 23 seconds. Especially at low wall temperatures, the total evaporation time would take several minutes. Therefore, the maximum recording time was limited to 50 seconds in order to reduce the expenditure of time for the data storage. In Figure 3, the wall film mass over time for the same measurement is depicted. When the spray impinges on the wall, the dynamic load cell measures the momentum of the spray during the first few milliseconds. This apparent load is around 100 times higher than the actual wall film mass even though the impact is mainly in the horizontal direction. After the resulting oscillations have subsided, the dynamic load cell delivers a true measurement of the wall film mass. These oscillations make it difficult to detect the entire wall film mass directly after the spray impingement. Therefore, the maximum wall film mass is defined as the first true measurement after the spray impact. The typical course of the wall film mass is a fast reduction at the beginning were the light boiling components evaporate and a smaller mass gradient once only high boiling components are left as wall film. The raw data suggests that the wall film mass reaches the zero line more quickly than the wall film area but this is in fact caused by the limited precision of the dynamic load cell with a standard deviation of less than $\pm 0.1 \mathrm{mg}$. Combining both measurement results of wall film area and mass an average wall film thickness can be calculated: 


$$
h(t)=m(t) /\left(A(t) \cdot \rho_{\text {Fuel }}\right)
$$

This represents a film that is evenly distributed over the whole wall film area. In this measurement the average wall film thickness in Figure $\mathbf{4}$ adopts a realistic value once the mass measurement is no longer affected by the spray momentum. The average thickness is quickly reduced in the first few seconds and remains almost constant after that. Only in the last second of evaporation does the thickness decrease to zero. This means that during the fast evaporation of the lower boiling components, wall film mass decreases more quickly than the wall film area. During the slow evaporation process that follows, both the area and the mass of the wall film decrease at a similar rate and at the end, mass is reduced more quickly again resulting in a reduced average wall film thickness. Another representation of the wall film can be found in Figure 7 where the amount of time that wall film covers each pixel, called dwell time, is depicted in a false colour image. Ignoring the local cooling effects of the wall film, this could represent a local film thickness since thinner wall films generally evaporate faster.

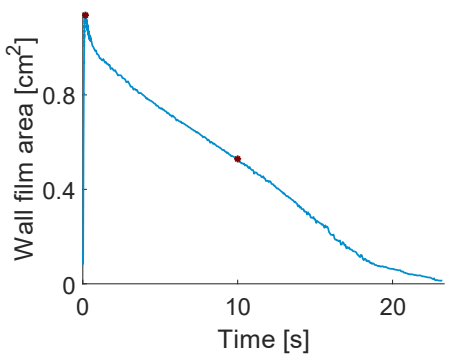

Figure 2. Wall film area over time $T_{\text {Fuel }}=393 \mathrm{~K}$ and $T_{\text {Wall }}=333 \mathrm{~K}$

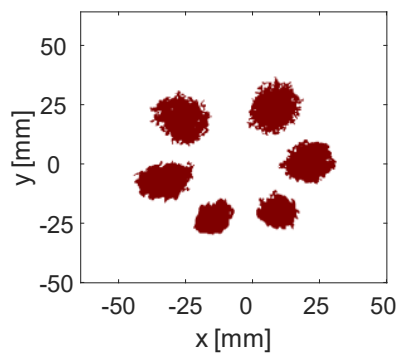

Figure 5. Image of the wall film with the maximum wall film area at $t=0.17 \mathrm{~s}-T_{\text {Fuel }}=393 \mathrm{~K}$ and $T_{\text {Wall }}=333 \mathrm{~K}$

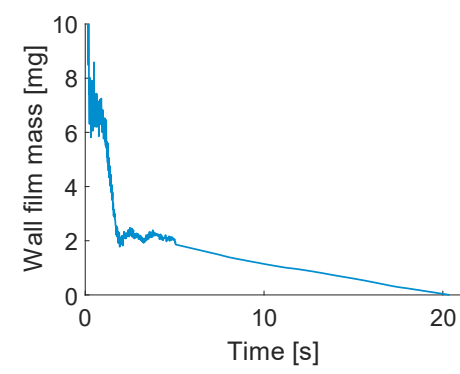

Figure 3. Wall film mass over time - $T_{\text {Fuel }}=393 \mathrm{~K}$ and $T_{\text {Wall }}=333 \mathrm{~K}$

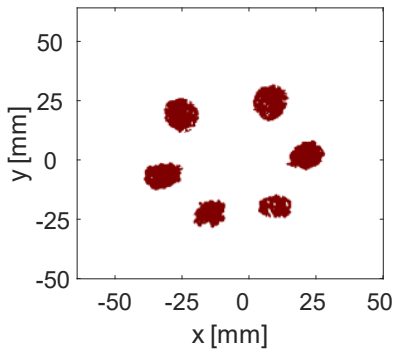

Figure 6. Image of the wall film at $t=10 \mathrm{~s}-T_{\text {Fuel }}=393 \mathrm{~K}$ and $T_{\text {Wall }}=333 \mathrm{~K}$

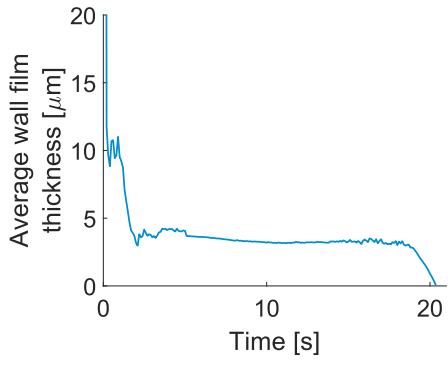

Figure 4. Average wall film thickness over time $-T_{\text {Fuel }}=393 \mathrm{~K}$ and $T_{\text {Wall }}=333 \mathrm{~K}$

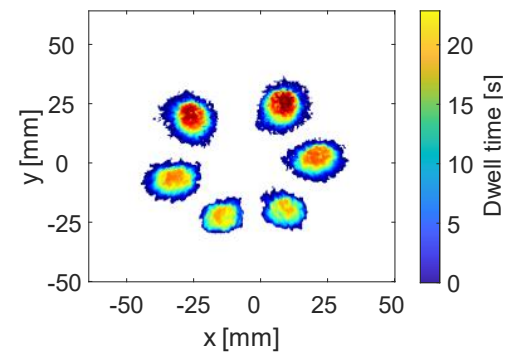

Figure 7. Dwell time image of the wall film $-T_{\text {Fuel }}=393 \mathrm{~K}$ and $T_{\text {Wall }}=333 \mathrm{~K}$

Further investigations presented here are concentrated on low temperature ranges of the wall to analyse the effects of a cold engine. The fuel temperature variation shows that an increase of the fuel temperature leads to an expected decrease in wall film area (Figure 8) and mass. After around 8 seconds, however, the wall film areas of the lower initial fuel temperatures show a steeper gradient. In the dwell time images in Figure $\mathbf{9}$ and in Figure $\mathbf{1 0}$ the dwell time per pixel is depicted in seconds. Since the recording of the images is 50 seconds at most, this is the highest possible dwell time. It becomes apparent that the maximal wall film area is larger for lower fuel temperatures although the dwell time in the wall film border is generally smaller which results in the steeper gradient of wall film area reduction. Causes for this behaviour are the faster evaporation of the hotter fuel during flight and an effect called "flash boiling". When superheated fuel enters the chamber, it begins changing aggregate state immediately. The 
necessary condition is a fuel temperature that exceeds the boiling point of the fuel or of some fuel component at the prevailing ambient pressure. The result is an improved atomization of the spray plumes which creates low pressure inside the individual plumes. If the plumes of a multi-hole injector are located closely together, low pressure is also generated near the centre of the spray and if the pressure drop is sufficient this results in a contraction of the spray and in an accelerated penetration and an accumulation of fuel near the spray and spray plume axis [7] - [8]. Since the boiling temperatures for $n$-Pentane, iso-Octane and n-Undecane are 309,372 and $469 \mathrm{~K}$ respectively at one atmosphere, flash boiling does not affect all components of the fuel equally. In the event of a degree of superheat sufficiently strong to result in spray contraction, the wall film is accumulated or concentrated in a narrow region around the spray axis.

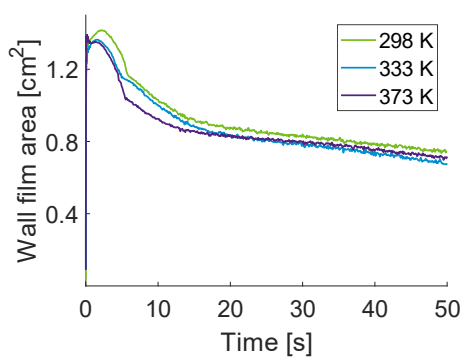

Figure 8. Wall film area over time - Variation of $T_{\text {Fuel }}$

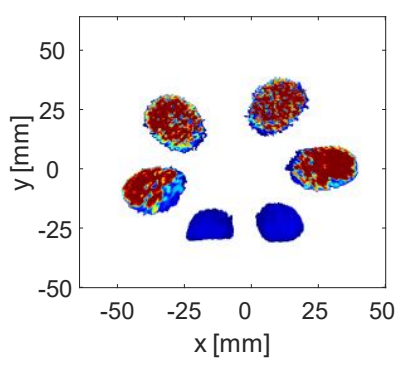

Figure 9. Dwell time in seconds $T_{\text {Fuel }}=298 \mathrm{~K}$

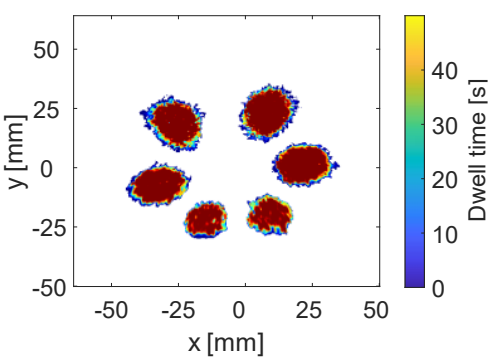

Figure 10. Dwell time in seconds $-T_{\text {Fuel }}=373 \mathrm{~K}$

The evaporation of fuel is accelerated at lower chamber pressures. This is visible in the wall film mass in Figure 12, where a large gradient increase becomes apparent in underatmospheric pressures. The distribution of the local film thicknesses changes with the chamber pressure.

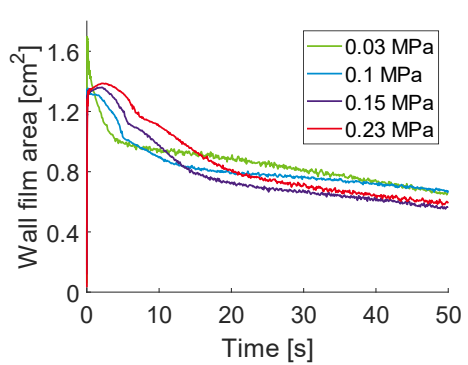

Figure 11. Wall film area over time - Variation of $p_{\text {Chamber }}$

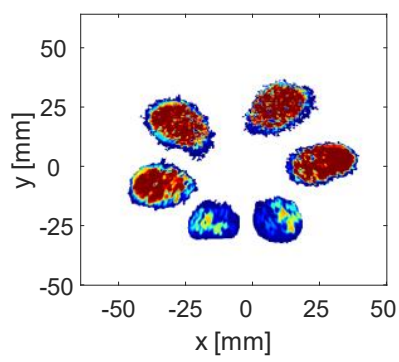

Figure 14. Dwell time in seconds $p_{\text {Chamber }}=0.03 \mathrm{MPa}$

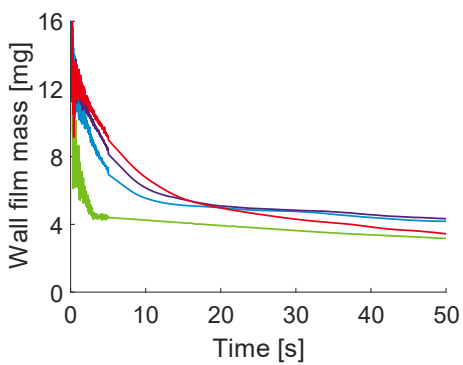

Figure 12. Wall film mass over time - Variation of $p_{\text {Chamber }}$

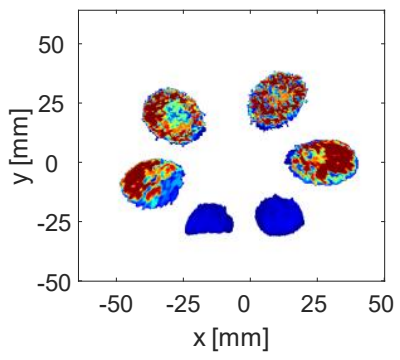

Figure 15. Dwell time in seconds $p_{\text {Chamber }}=0.15 \mathrm{MPa}$

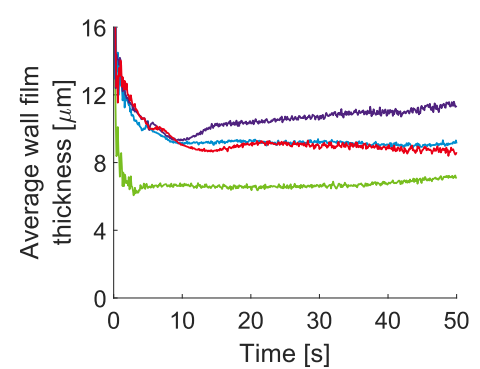

Figure 13. Average wall film thickness over time - Variation of

$p_{\text {Chamber }}$

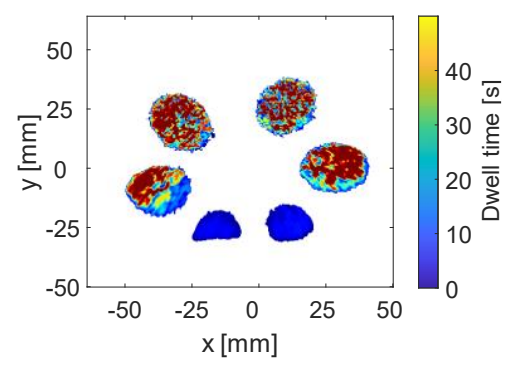

Figure 16. Dwell time in seconds

$-p_{\text {Chamber }}=0.23 \mathrm{MPa}$ 
This is visible comparing the dwell time images for $0.03,0.15$ and $0.23 \mathrm{MPa}$ chamber pressure in Figure 14 to Figure 16 respectively as well as in the average wall film thickness in Figure 13. Over time, the average thickness increases for chamber pressures up to $0.15 \mathrm{MPa}$, then decreases again. The local thickness distribution over this variation changes from thin wall film edges (0.03 MPa) to thin wall film centres $(0.15 \mathrm{MPa})$ and back to thin edges $(0.23 \mathrm{MPa})$. The chamber pressure is another parameter which can enhance the flash boiling effect. Due to lower chamber pressures the boiling point of a fuel is lowered which in turn results in a contracting spray and spray plumes for lower chamber pressures. These effects lead to a local accumulation of wall film with small thicknesses in the wall film border regions for low chamber pressures. The evaporation in these regions will therefore be fast while the bulk of the wall film mass will take more time to evaporate. The local differences in wall film distribution and the increased wall film areas for high chamber pressures leads to a faster evaporation of the wall film at $0.23 \mathrm{MPa}$ although the overall evaporation is slowed down due to the increased boiling points in comparison to the wall film at $0.15 \mathrm{MPa}$. Another contrary factor is the increased heat transfer coefficient due to increased chamber pressures which in turn accelerates the heat transfer between the wall film and the surrounding nitrogen and increases the evaporation.

\section{Model Comparison}

The evaporation model published by Y. Yan et al. in [9] was adapted to simulate the evaporation behaviour of the measured wall films. The wall film model is a one-dimensional analytical analysis of the heat conduction between the wall film and the wall, the heat conduction inside the wall film and the convective heat transfer to the surrounding gas which lead to the evaporation of the wall film. It was implemented for films on the cylinder walls of a diesel engine with a thickness of less than $100 \mu \mathrm{m}$. A constant wall film thickness over the whole wall film area and a diesel fuel with high saturated temperature is considered assuming instantaneous mixing of the components. The model was adapted to fit the surrounding conditions of the measurement set-up described earlier. Moreover, real wall film areas and thickness distributions of six-hole nozzles were considered utilizing the dwell time images from before. With the maximum wall film mass, obtained by the load cell measurements a pixelwise wall film mass was calculated depending on the dwell time of each pixel:

$$
m_{i}=\sum_{i=1}^{n}\left(\frac{m}{n} \cdot \frac{t_{d w e l l, i}}{t_{\text {evap }, \max }}\right)
$$

There are multiple simplifications made to get the initial conditions which go into the analytical solution of the evaporation behaviour. At first, the wall film mass at the beginning of the measurements is superposed by the effect of the spray momentum. It takes several milliseconds until this effect subsides and only the wall film mass is measured. This means that the initial wall film mass for the model is considered too low. Another unknown factor is the wall film temperature at the beginning of the measurement. Since the only known is the fuel temperature inside the nozzle, it is used as the initial condition of the wall film temperature. Mainly depending on the chamber temperature, the spray temperature changes during flight which was measured in [9] and is currently neglected in the model. The same issue arises for the fuel composition of the wall film. Since only the initial fuel composition before the injection is known, it is considered the initial composition of the wall film as well. Due to the evaporation of the spray, the composition of the fuel will change until wall film forms. This could have a strong effect on evaporation times, since the ratio of the higher boiling fuel components will 
rise in the wall film, leading to a decelerated evaporation. The dwell time images represent another limitation. Since maximum number of images is limited to an evaporation time of 50 seconds, whereas for various experiments the evaporation takes longer, all pixels with a maximum dwell time are considered to have the same amount of wall film mass. Furthermore, when fuel spray hits a wall, there are local cooling effects of the wall due to heat transfer and the enthalpy of evaporation [11]. So, while the overall temperature change of the wall is considered using the measurement results from the infrared sensor, the local temperature changes are neglected in this model which leads to some deviation between the measurements and the model. Additionally, the immediate translation between dwell time and fuel mass per pixel is not completely correct. At a distance between the wall and the nozzle of $55 \mathrm{~mm}$ and a chamber pressure of $0.03 \mathrm{MPa}$, the following figures emphasise how flash boiling affects fuel wall films.

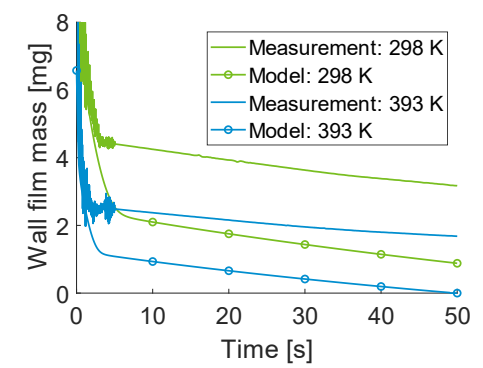

Figure 17. Wall film mass over time - Variation of $T_{\text {Fuel }}$ at $p_{\text {Chamber }}=0.03 \mathrm{MPa}$ and $d_{\text {Inj }}=55 \mathrm{~mm}$

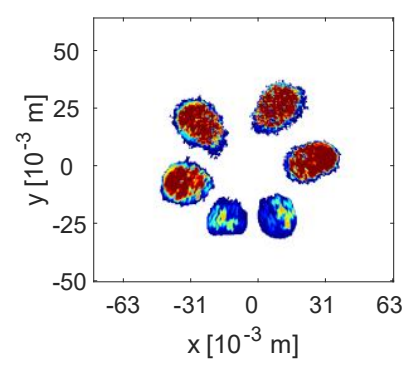

Figure 19. Dwell time in seconds $-T_{F u e l}=298 \mathrm{~K}$ and $p_{\text {Chamber }}=0.03 \mathrm{MPa}$

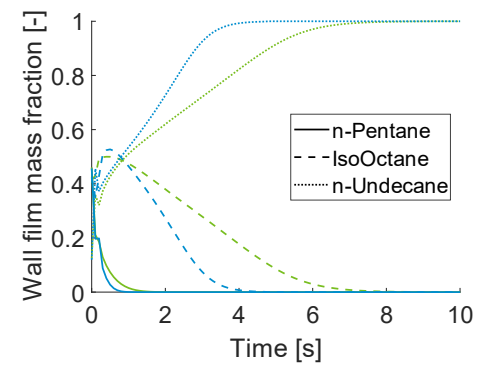

Figure 18. Wall film mass fractions over time Variation of $T_{\text {Fuel }}$ at $p_{\text {Chamber }}=0.03 \mathrm{MPa}$ and $d_{\text {Inj }}=$ $55 \mathrm{~mm}$

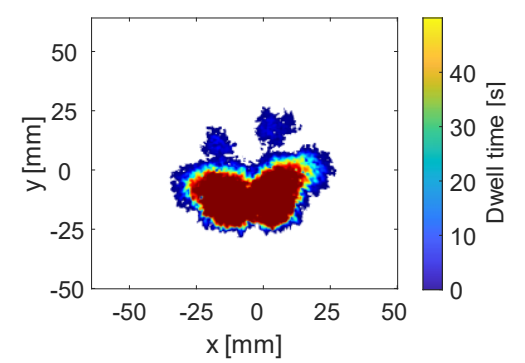

Figure 20. Dwell time in seconds $-T_{\text {Fuel }}=393 \mathrm{~K}$ and $p_{\text {Chamber }}=0.03 \mathrm{MPa}$

The wall film mass in Figure $\mathbf{1 7}$ decreases with increasing fuel temperatures. For the wall film area, the behaviour is not linear due to flash boiling effects. In Figure $\mathbf{1 9}$ and Figure $\mathbf{2 0}$ this change of wall film area caused by flash boiling is visible. Comparing the model results to the measurement results, it becomes apparent that there are some differences. Looking at the results in Figure 17, the larger mass gradient of wall film mass in the beginning of the modelled experiment lasts longer whereby the gradient after a few seconds is similar to the measurement. The underestimated initial fuel mass could lead to that difference as well as the initial assumed fuel composition inside the wall film. In Figure 18, the mass fractions of the fuel components in the liquid wall film from the model are depicted over time. For a chamber pressure of $0.03 \mathrm{MPa}, \mathrm{n}$-Pentane is fully evaporated in under one second, and iso-Octane after four seconds. At this time, the wall film mass gradient of the model changes a lot. If a different fuel composition with a lower content of low boiling components was chosen for the model, this gradient change would happen sooner and could therefore explain the differences between the model and the experiment. This difference between the measurement and the model is smaller for an increased fuel temperature. The maximum wall film mass is smaller 
for higher fuel temperatures and therefore the underestimation of the initial wall film mass and the differences in fuel composition are smaller as well.

\section{Conclusions}

Two different measurement techniques to evaluate the evaporation behaviour of fuel wall films were presented. The results for the variation of the fuel temperature and the chamber pressure were discussed and compared to the results from an adapted evaporation model from the literature. The differences of the experimental and of the modelled results were analysed and their origins considered. While the mass evaporation gradients show good alignment, there are differences in the measured and modelled wall film masses. there are differences in the measured and modelled wall film masses. Selective evaporation of the different fuel components during the trajectory of the spray might be part of the explanation, as it would lead to an unknown starting composition of the liquid that makes up the wall films. Further tests with single-component fuels could be conducted in order to separate the influence of other parameters, like the maximum wall film mass. Another measurement technique like laser-induced fluorescence could be used under selected conditions to measure the local wall film thicknesses thus improving the model accuracy.

\section{Nomenclature}

$\begin{array}{llll}A & \text { wall film area }\left[\mathrm{m}^{2}\right] & d_{I n j} & \text { nozzle-wall distance }[\mathrm{m}] \\ h & \text { wall film thickness }[\mathrm{m}] & m & \text { wall film mass }[\mathrm{kg}] \\ m_{i} & \text { wall film mass of pixel } i[\mathrm{~kg}] & m_{\text {Inj }} & \text { injected fuel mass }[\mathrm{kg}] \\ n & \text { number of wall film pixels }[-] & p_{\text {Chamber }} & \text { chamber pressure }[\mathrm{Pa}] \\ p_{\text {Fuel }} & \text { fuel pressure }[\mathrm{Pa}] & t & \text { time [s] } \\ t_{d \text { well }, i} & \text { dwell time of pixel } i[\mathrm{~s}] & t_{\text {evap,max }} & \text { max. evaporation time }[\mathrm{s}] \\ T_{\text {Fuel }} & \text { fuel temperature }[\mathrm{K}] & T_{\text {Wall }} & \text { wall temperature }[\mathrm{K}]\end{array}$

\section{References}

[1] A. Kufferath, W. Wiese, W. Samenfink, H. Dageförde, T. Knorsch und P. Jochmann, Mar. 10.-11. 2015, Fuel systems for IC engines, International conference.

[2] C. Bai, A. Gosman, 1996, Journal of Engines, 105 (3), pp. 782-796.

[3] S. Y. Lee, S. U. Ryu, 2006, Journal of Mechanical Science and Technology, 20 (8), pp. 1101-1117.

[4] C. Tibiriçá, F. do Nascimento, G. Ribatski, 2010, Experimental Thermal and Fluid Science, 34, pp. 463-473.

[5] L. Itani, G. Bruneaux, A. Di Lella, C. Schulz, 2015, Proceedings of the Combustion Institute, 35, pp. 2915-2922.

[6] G. Lamanna, H. Kamoun, B. Weigand, J. Steelant, 2014, International Journal of Multiphase Flow, 58, pp. 168-184.

[7] P. Leick, M. Schmitt, T. Kubis, K. G. Stapf, T. Gawlica, June 26.-27. 2018, 13th International AVL Symposium on Propulsion Diagnostics, Baden-Baden.

[8] Y. Yan, H. Liu, M. Jia, M. Xie, H. Yin, "A one-dimensional unsteady wall film evaporation model," International Journal of Heat and Mass Transfer, 2015.

[9] H. Golzke, P. Leick, A. Dreizler, 2016, Quantitative InfraRed Thermography Journal, 13 (1), pp. 50-69.

[10] A. Mendieta, P. Dragomirov, F. Schulz, F. Beyrau, W. Samenfink, E. Schünemann, 2018, SAE Technical Paper (2018-01-0273).

[11] D. Kuhnke, "Spray/Wall-Interaction Modelling by Dimensionless Data Analysis", 2004. 